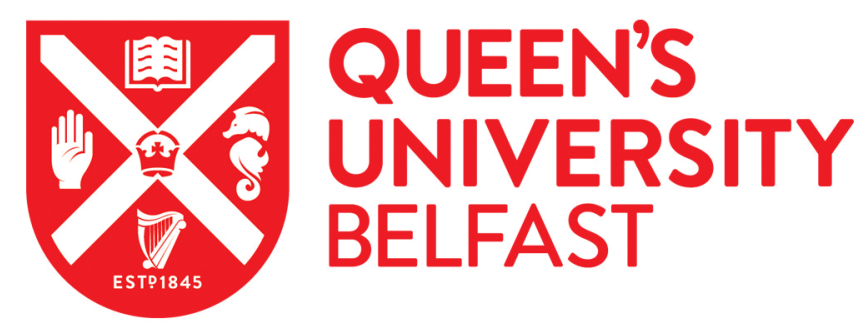

\title{
Identifying psychological outcomes in families of Five Eyes alliance armed forces Veterans: A systematic review
}

Armour, C., Spikol, E., McGlinchey, E., Gribble, R., Fear, N. T., \& Murphy, D. (2021). Identifying psychological outcomes in families of Five Eyes alliance armed forces Veterans: A systematic review. Journal of Military, Veteran and Family Health. https://doi.org/10.3138/jmvfh-2021-0025

Published in:

Journal of Military, Veteran and Family Health

Document Version:

Publisher's PDF, also known as Version of record

Queen's University Belfast - Research Portal:

Link to publication record in Queen's University Belfast Research Portal

Publisher rights

( ) Her Majesty the Queen in Right of Canada, as represented by the Minister of National Defence, 2021

This work is made available online in accordance with the publisher's policies. Please refer to any applicable terms of use of the publisher.

\section{General rights}

Copyright for the publications made accessible via the Queen's University Belfast Research Portal is retained by the author(s) and / or other copyright owners and it is a condition of accessing these publications that users recognise and abide by the legal requirements associated with these rights.

Take down policy

The Research Portal is Queen's institutional repository that provides access to Queen's research output. Every effort has been made to ensure that content in the Research Portal does not infringe any person's rights, or applicable UK laws. If you discover content in the Research Portal that you believe breaches copyright or violates any law, please contact openaccess@qub.ac.uk. 


\title{
Identifying psychological outcomes in families of Five Eyes alliance armed forces Veterans: A systematic review
}

\author{
Cherie Armoura $^{\mathrm{a}}$, Eric Spikol ${ }^{\mathrm{a}}$, Emily McGlinchey ${ }^{\mathrm{a}}$, Rachael Gribble ${ }^{\mathrm{b}}$, Nicola T. Fear ${ }^{\mathrm{b}}$ \\ and Dominic Murphyc
}

\begin{abstract}
Introduction: The psychological effects of military service and lifestyle are not confined to individual service members, as there are also potential consequences for the mental health and well-being of military family members. Adult children and intimate partners of ex-service members can share this risk but may be overlooked both as potential research populations and in the planning of policy and outreach/treatment programs. This systematic review aimed to identify the psychological health outcomes of partners and adult children of ex-service members in Five Eyes alliance countries: Australia, Canada, New Zealand, United Kingdom, and the United States. Methods: Search protocols were used in aggregate databases and related journals for peer-reviewed literature. A total of 24 studies met inclusion criteria $(\mathrm{N}=18$ quantitative, $\mathrm{N}=6$ qualitative). Quantitative studies were summarized by narrative synthesis and qualitative data was analyzed using a descriptive-interpretive approach. Results: Intimate partners had higher prevalence rates of anxiety, depression, and posttraumatic stress disorder (PTSD) than population norms and were more likely to suffer distress because of the Veteran's mental health issues. Adult children were at increased risk for anxiety, depression, alcohol/ substance misuse, and PTSD compared to population norms. Four themes were identified from the qualitative data: personal feelings and internal emotions, Veteran-oriented, help and support, and acting as a unit. Discussion: There are substantial gaps in the literature regarding the mental health and well-being of intimate partners and adult children of ex-service members in Five Eyes alliance countries. Future research is needed to address psychological outcomes among families after leaving the military.
\end{abstract}

Key words: adult children, Australia, Canada, Five Eyes, Military, military family, mental health, New Zealand, PTSD, psychological outcomes, Veterans, United Kingdom, U.S.

\section{RÉSUMÉ}

Introduction : Les effets psychologiques du service et du mode de vie militaires ne se limitent pas aux militaires euxmêmes, mais peuvent avoir des conséquences sur la santé mentale et le bien-être des membres de leur famille. Les enfants adultes et les partenaires intimes d'anciens militaires peuvent partager ce risque, mais peuvent être oubliés à la fois à titre de populations de recherche potentielles et lors de la planification des politiques et des programmes de diffusion et de traitement. Cette analyse systématique visait à déterminer la santé psychologique des partenaires et des enfants adultes d'anciens militaires dans les pays de l'alliance Five Eyes : l'Australie, le Canada, la Nouvelle-Zélande, le Royaume-Uni et les États-Unis. Méthodologie : Les chercheurs ont utilisé des protocoles de recherche pour regrouper les éléments de bases de données et de revues connexes afin d'extraire les publications révisées par un comité de lecture. $\mathrm{Au}$ total, 24 études respectaient les critères d'inclusion ( $\mathrm{n}=18$ quantitatives, $\mathrm{n}=6$ qualitatives). Les chercheurs ont résumé les études quantitatives par des synthèses narratives et ont analysé les données qualitatives par une approche de description-interprétation. Résultats : Les partenaires intimes présentaient un plus fort taux d’anxiété, de dépression et de trouble de stress post-traumatique (TSPT) que l'ensemble de la population et étaient plus susceptibles de souffrir de détresse à cause des problèmes de santé mentale des vétéran(e)s. Les enfants adultes étaient plus à risque d'anxiété, de dépression, de mésusage d'alcool et de substances psychoactives et de TSPT que l'ensemble de la population. Les

a Research Centre for Stress, Trauma and Related Conditions (STARC), Queen's University Belfast, Belfast, Northern Ireland, United Kingdom

b King's Centre for Military Health Research, King's College London, London, United Kingdom

c Research Department, Combat Stress, Leatherhead, United Kingdom

Correspondence should be addressed to Cherie Armour, Queen's University Belfast, David Keir Building, 18-30 Malone Road, Belfast, Northern Ireland, United Kingdom, BT9 5BN. Telephone: +44 (0)289097 4387. Email: c.armour@qub.ac.uk 
chercheurs ont dégagé quatre thèmes des données qualitatives : les sentiments personnels et les émotions internes, l'orientation vers les vétéran(e)s, l'aide et le soutien et le fait d'agir comme une unité. Discussion : Les chercheurs constatent des lacunes importantes dans les publications sur la santé mentale et le bien-être des partenaires intimes et des enfants adultes d'anciens membres du service militaire des pays de l'alliance Five Eyes. D’autres recherches devront être réalisées pour approfondir la situation psychologique des familles après le passage à la vie civile.

Mots-clés : Australie, Canada, enfants adultes, E.-U., famille des militaires, Five Eyes, militaire, Nouvelle-Zélande, résultats psychologiques, Royaume-Uni, santé mentale, TSPT, vétéran(e)s

\section{LAY SUMMARY}

Military service can affect the psychological health and well-being of ex-service members and their families. Most research prioritizes active duty families or Veterans, with spouses/intimate partners and adult children of Veterans often overlooked. This study reviewed all previous research on the psychological health of Veteran families within the Five Eyes alliance countries of Australia, Canada, New Zealand, the United Kingdom, and the United States. It found spouses/intimate partners had higher rates of anxiety, depression, and posttraumatic stress disorder (PTSD) compared to national rates and were more likely to feel distress when their Veteran partner had mental health issues. Adult children were at higher risk for anxiety, depression, alcohol/substance misuse, and PTSD compared to national rates. Four themes identified were: personal feelings and internal emotions, Veteran-oriented, help and support, and acting as a unit. Due to the scarce available research, further studies are needed to address psychological outcomes among military Veteran families.

\section{INTRODUCTION}

Military service and armed conflict can have adverse effects on some service members and family members proximal to them..$^{1-6}$ Indeed, when an ex-service member experiences an adverse mental health outcome such as posttraumatic stress disorder (PTSD), their intimate partners and children are at risk for secondary traumatization. ${ }^{7-8}$ Decades of research have recognized the considerable public health implications of increased risk for Veterans' family members. ${ }^{9-11}$ However, research focused on ex-service members' intimate partners is far less prevalent than research examining ex-service personnel, while research examining military-connected children is often in a developmental context ${ }^{10,12}$ or focused on childhood/adolescence, ${ }^{13-14}$ leaving aside psychological outcomes in now-adult children. Furthermore, the literature is skewed towards active duty service members and their families, with fewer studies examining these populations after they transition out of the armed forces. ${ }^{11,15}$ As active duty service members have full access to military support/resources in a military system, and Veterans must make use of civilian resources and public support systems, the two populations differ significantly.

The Five Eyes alliance is an organization of member countries party to the United Kingdom-United States of America Agreement (UKUSA) intelligence treaty. The combined military population of these countries is estimated at 2.6 million. ${ }^{16}$ The addition of family members significantly increases population size and results in a substantial population who are potentially at risk. This population is estimated at 1,596,169 in the United
States ${ }^{17}$ and 99,716 in Canada. ${ }^{18}$ Stigma surrounding mental health issues and help-seeking is endemic in military culture, ${ }^{19}$ introducing additional barriers to care and treatment for those in distress. An individual serving their country should be afforded all due care and the same must apply to partners and children, who often have little choice in the nature of their family member's military service, including deployments.

Research into the mental health and well-being of intimate partners of serving and ex-serving military personnel has concentrated on their higher levels of secondary traumatization/PTSD, $, 5,7,20$ caregiver burden, ${ }^{21-24}$ and adverse mental health outcomes, ${ }^{6,25-27}$ including alcohol/substance misuse. ${ }^{28-29}$ These studies have shown a spectrum of effects and effect intensity as a result of the intimate partner's association with their service member partner and exposure to the military lifestyle. These studies highlight the intimate partner carries the burden of not only caring for their spouse and family, but also balancing self-care. ${ }^{30}$ This population has unique service needs and barriers to accessing help, primarily stigma in the military community among service members $^{19,31}$ and intimate partners. ${ }^{25,32}$

Studies examining the effects of a military parent on a child population have focused on behavioural/ psychological impact in young children, ${ }^{15,33-35}$ in middle children and adolescents, ${ }^{36-38}$ and on the family as a unit. ${ }^{39-40} \mathrm{~A}$ body of literature exists on the transgenerational transmission of trauma from the Veteran to the child, ${ }^{8,41}$ though from an interactional and not epigenetic perspective. Research interest in academic and mental 
health outcomes in childhood/adolescence is high for this population but less literature exists on the ongoing challenges children of Veterans may face after 18 years of age and throughout adulthood. ${ }^{11}$ Research focusing on adult children of Veterans could identify if being a military-connected child carries increased risks for specific psychological outcomes, which could be incorporated into early intervention programs. With the children of Veterans of contemporary conflicts beginning to reach this age, it is imperative future research focuses on this group to ensure their unique service needs are met.

The aim of this systematic review was to explore the existing literature to understand the body of research on intimate partners and adult children of Veterans to identify gaps and inform future research. This review centred on countries of the Five Eyes alliance due to a common language, similar military involvement/ deployment patterns, and similarities in society and culture. It described associations between military service and family member psychological health (anxiety, depression, alcohol/substance misuse, and PTSD) using a narrative synthesis approach for quantitative data and a meta-synthesis for qualitative data.

\section{METHODS}

\section{Protocol}

A detailed protocol was written explaining the review methods, questions, context, definitions, search strategy, inclusion/exclusion criteria, quality appraisal, data extraction and synthesis. This protocol was submitted to PROSPERO (the International Prospective Register of Systematic Reviews), an online database of systematic review protocols submitted prospectively to maintain researcher integrity. The protocol was approved under the registration CRD42020221166 (available at www.crd.york.ac.uk/prospero/display_record.php? ID $=$ CRD 42020221166).

\section{Search strategy}

The electronic databases of MEDLINE, PsychINFO, EMBASE, EBSCO, Informit, PILOTS (now PTSDpubs), and Web of Science were identified as viable resources and searched in November 2020. Search strings were designed and run sequentially to specify: 1) a military context, 2) the populations of interest, 3) adverse mental health outcomes and, 4) general/positive mental health outcomes (see Appendix 1).

Specific military-related journals were also searched, including BMJ Military Health, Military Medicine,
Military Behavioural Health, Armed Forces and Society, and the Journal of Military, Veteran and Family Health, as well as the reference sections of identified papers. These searches were conducted in compliance with Joanna Briggs Institute guidelines. ${ }^{42}$

\section{Population definitions}

The target population was individuals belonging to military families in the Five Eyes alliance countries in which the service member was considered a Veteran, ex-service member, or retired. Military Veterans/ex-service members were defined as those who had served at least one day full-time in the armed forces and were now no longer serving and who may or may not have been deployed in combat or peacekeeping roles and excluded those who only served as reservists. Family members included current and past intimate partners (married or unmarried; hereafter partners) and adult children ( $\geq 18$ years), biologically related to the ex-service member or not, of ex-serving military members. Parents, siblings, and children of ex-service members $<18$ years were excluded.

\section{Study selection criteria}

Study inclusion criteria were:

- full or partial population of current/past partners of Veterans, adult children of Veterans, or a family unit including both

- population from a Five Eyes alliance country

- estimates of psychological/mental health outcomes defined as PTSD, anxiety, depression, alcohol/ substance misuse, risk, and/or resilience

- publication in a peer-reviewed journal

- publication in English

- publication between the years 2000 and 2020 (inclusive)

Studies were excluded if they did not fit the inclusion criteria, publication occurred before the year 2000 or after 2020 , they evaluated interventions, they reviewed military policy/treatment programs, they used samples containing the target population (partners and adult children) and excluded individuals (Veterans, active duty family members, other family) without delineation of group differences in the results, and they measured outcomes only in the Veteran. Academic publications were prioritized over government/third party reports due to accessibility/availability issues.

Source selection was performed by two reviewers, with blinded title and abstract screening followed by full-text screening. A third reviewer was involved in 
case of disagreements. The process was piloted prior to undertaking full screening, with a random sample of 25 sources selected, and full-text screening occurring after $75 \%$ agreement. Search results were exported to Endnote for evaluation and Covidence for screening. A total of 29,341 results were sourced from the initial search, 84 results qualified for full-text screening and 24 studies met criteria for inclusion (Figure 1, Table 1).

\section{Data extraction}

Data extracted from each study included: authors, year of publication, population/sample size and type, study design, study focus, and findings (Table 1). Data extracted for analysis included (when available): journal title, study title, country of origin, conflict, response rate, gender totals, age range/mean, armed forces branch, last known rank of ex-service member, and time in service

\section{PRISMA 2009 Flow Diagram}
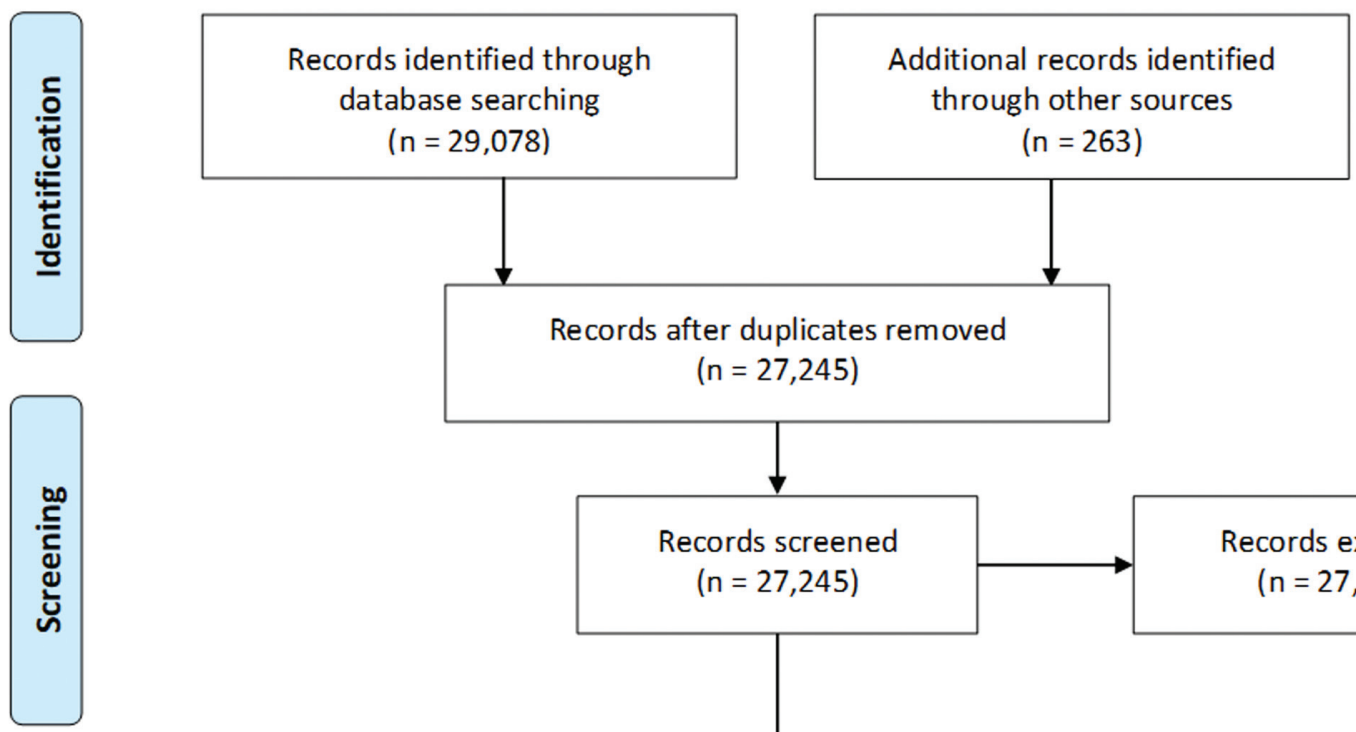

Records after duplicates removed

( $n=27,245)$
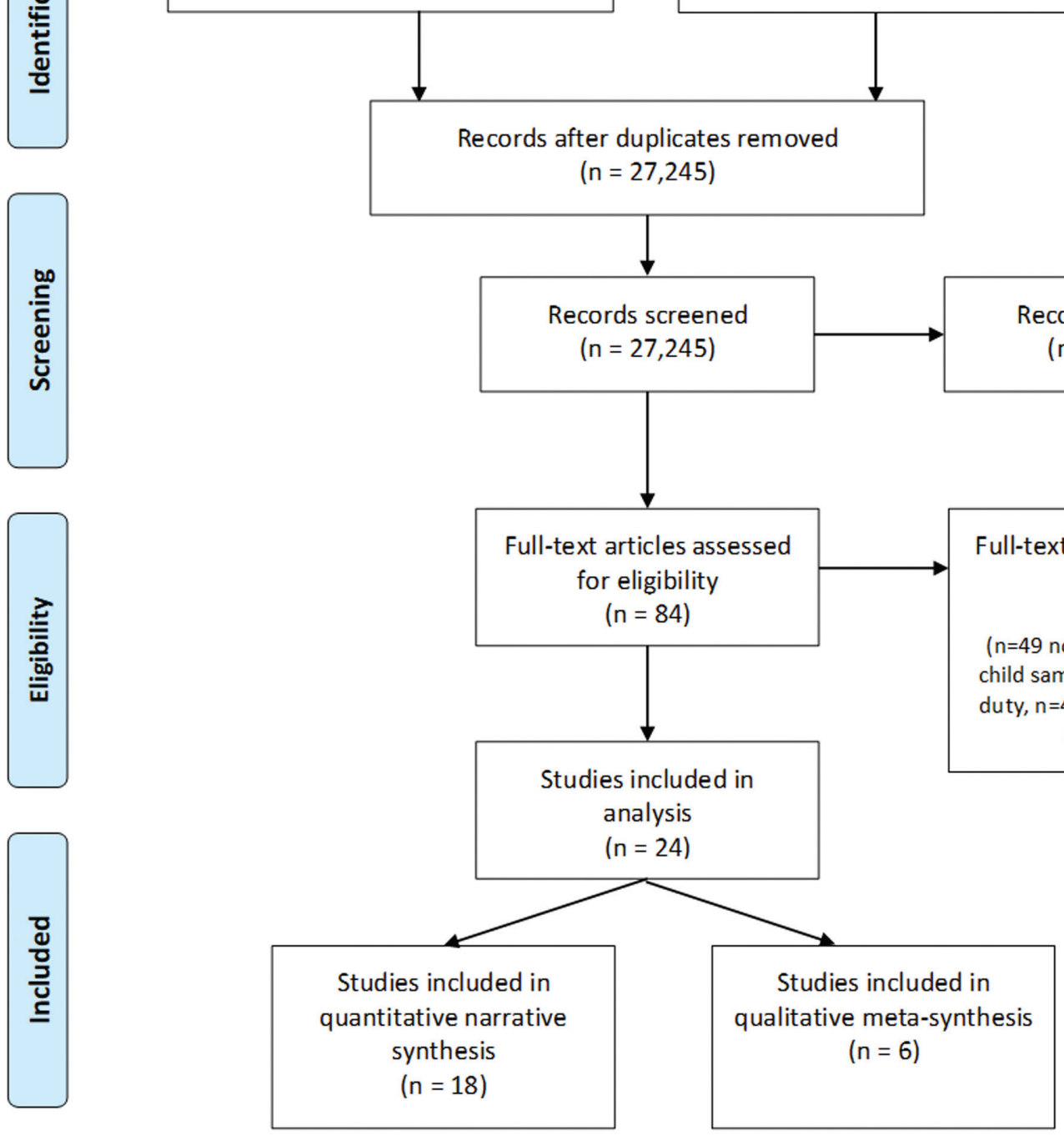

Figure 1. PRISMA flow diagram, adapted from Moher et al., 2009; * $(n=49$ non 5 -E country, $n=1$ child population $<18$, $\mathrm{n}=1$ active duty, $\mathrm{n}=4$ mixed sample, $\mathrm{n}=5$ reviews) 
of ex-service member. A $10 \%$ check was performed on the data with a third reviewer available in the event of disagreement.

\section{Quality appraisal}

A quality appraisal tool adapted from The Quality Assessment Tool for Observational Cohort and CrossSectional Studies ${ }^{43}$ (see Appendix 2) was used to evaluate included studies.

\section{Data synthesis strategy}

Both quantitative and qualitative articles were included. A narrative synthesis was selected for the quantitative findings. This word-based technique summarizes results from multiple studies where differences in methodology preclude a more traditional meta-analysis and uses narrative to describe the findings of multiple studies as an aggregate synthesis. ${ }^{44}$ While this method has been criticized for lacking transparency, ${ }^{45(\mathrm{p} .7)}$ applying a rigorous framework of narrative synthesis in an analysis increases replicability ${ }^{46-47}$ and is well suited to identify the landscape of the extant literature. ${ }^{48}$

A meta-synthesis was selected to analyze the qualitative findings, specifically a descriptive-interpretive approach $^{49-50}$ due to its flexible accommodation of multiple analytic styles. This process involves categorizing the data by domains, nominating an evaluation metric of meaning units, evaluating data based on these units, forming emergent categories, and synthesizing findings. ${ }^{50}$ As interpretive phenomenological analysis $(\mathrm{N}=3)$, thematic analysis $(\mathrm{N}=2)$, and grounded theory $(\mathrm{N}=1)$ were represented, the descriptive-interpretive approach provided a framework for synthesizing both descriptive and interpretive results within a larger work, tailoring the analysis for the review's goals and aims. ${ }^{51}$

\section{RESULTS}

\section{General findings}

The 24 studies reviewed (Table 1) detailed research in Australia $(\mathrm{N}=12)$, the U.S. $(\mathrm{N}=8)$, Canada $(\mathrm{N}=2)$, and the UK $(\mathrm{N}=2)$. Samples ranged from 3-1,966 and were predominantly female, with 13 studies reporting a completely female population and 11 reporting at least $>50 \%$ female. Two did not report gender. Partner ages ranged from 21-83 years (Mean 50.10 years) and adult child ages ranged from 18-60 (Mean 37.76 years). Conflict was reported in 15 studies $(\mathrm{N}=14$, Vietnam, $\mathrm{N}=1$, post $-9 / 11$ conflicts). Military service branch of ex-serving members was reported in nine studies
( $\mathrm{N}=3$, navy/army/air force, $\mathrm{N}=5$, army, $\mathrm{N}=1$, army/ air force), with three studies reporting Veteran rank, all at $>80 \%$ enlisted. Time in service of ex-serving members was noted in two studies ( $\mathrm{N}=1,54 \%$ served $>2$ years, $N=1$, from 2-38 years) and time since separation from service of ex-serving members was recorded in only one study (> 10 years).

\section{Narrative analysis of quantitative studies}

Quantitative studies $(\mathrm{N}=18)$ were assessed by study population (partners: $N=12$, children: $N=6$ ) and psychological outcome. Depression was the most frequently examined $(N=11)$, followed by anxiety $(N=9)$, general distress $(\mathrm{N}=8)$, alcohol/substance misuse $(\mathrm{N}=6)$, and PTSD $(\mathrm{N}=5)$. Multiple scales and indices were used to assess the psychological outcomes and details can be found in the supplementary materials.

\section{Partners of Veterans}

Most of the partner studies focused on partners of Veterans with PTSD and the secondary effects of the disorder on the partner. Campbell and Renshaw (United States), ${ }^{52}$ MacDonell et al. (Australia), ${ }^{53}$ and MangunoMire et al. (United States) ${ }^{54}$ focused on the relationship between Veteran PTSD and partner distress. Conflictspecific Veteran communication increased partner distress only when Veteran PTSD was at/surpassed the clinical threshold. ${ }^{52}$ Veteran PTSD had a positive association with partner distress, impacting dyadic adjustment, life satisfaction, ${ }^{53}$ and caregiver burden. ${ }^{54}$

Several studies covered multiple psychological outcomes in Australian partner populations as compared to national prevalence rates. MacDonell, Bhullar, and Thorsteinsson (Australia) ${ }^{55}$ examined anxiety, depression, and stress in four samples of military partners, with partners of ex-service members showing mean scores for anxiety $(g=0.79)$, depression $(g=0.66)$, and stress $(g=0.80)$ far more than population norms. O’Toole et al. (Australia) ${ }^{56}$ found higher prevalence rates of 11 out of 17 psychopathologies in a partner sample, with generalized anxiety disorder associated with Veteran suicidal ideation and severe single-episode and moderate recurrent depression associated with combat-related Veteran PTSD and battle casualty, respectively. Veteran PTSD was also uniquely predictive of suicidality for both Veterans and their partners. ${ }^{57}$

Exploring psychopathology and help-seeking beliefs in partners of Veterans, Murphy, Palmer, and Busuttil (United Kingdom) ${ }^{58}$ found $45 \%$ of partners reached the clinical threshold for alcohol misuse, 39\% for depression, 


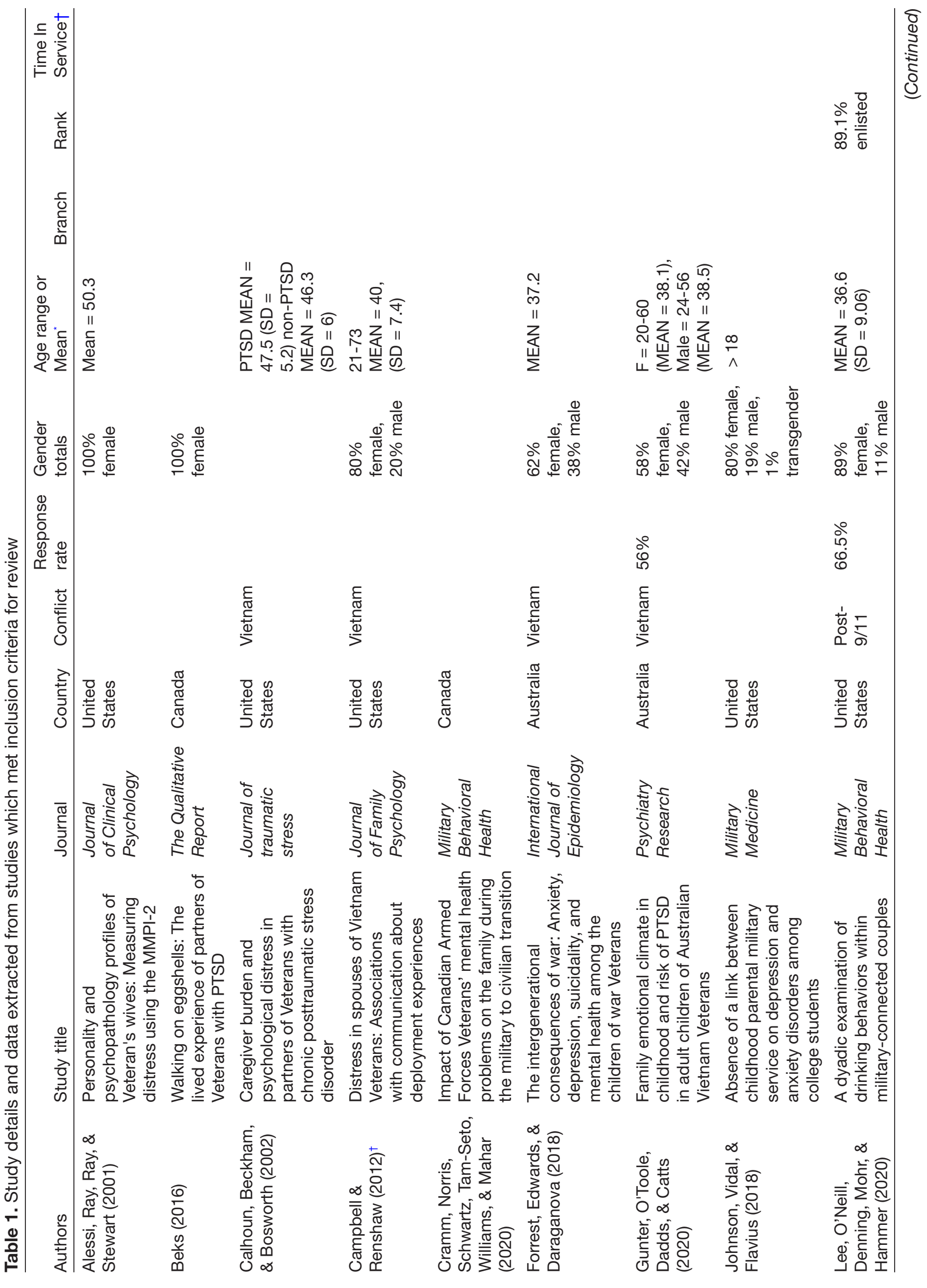




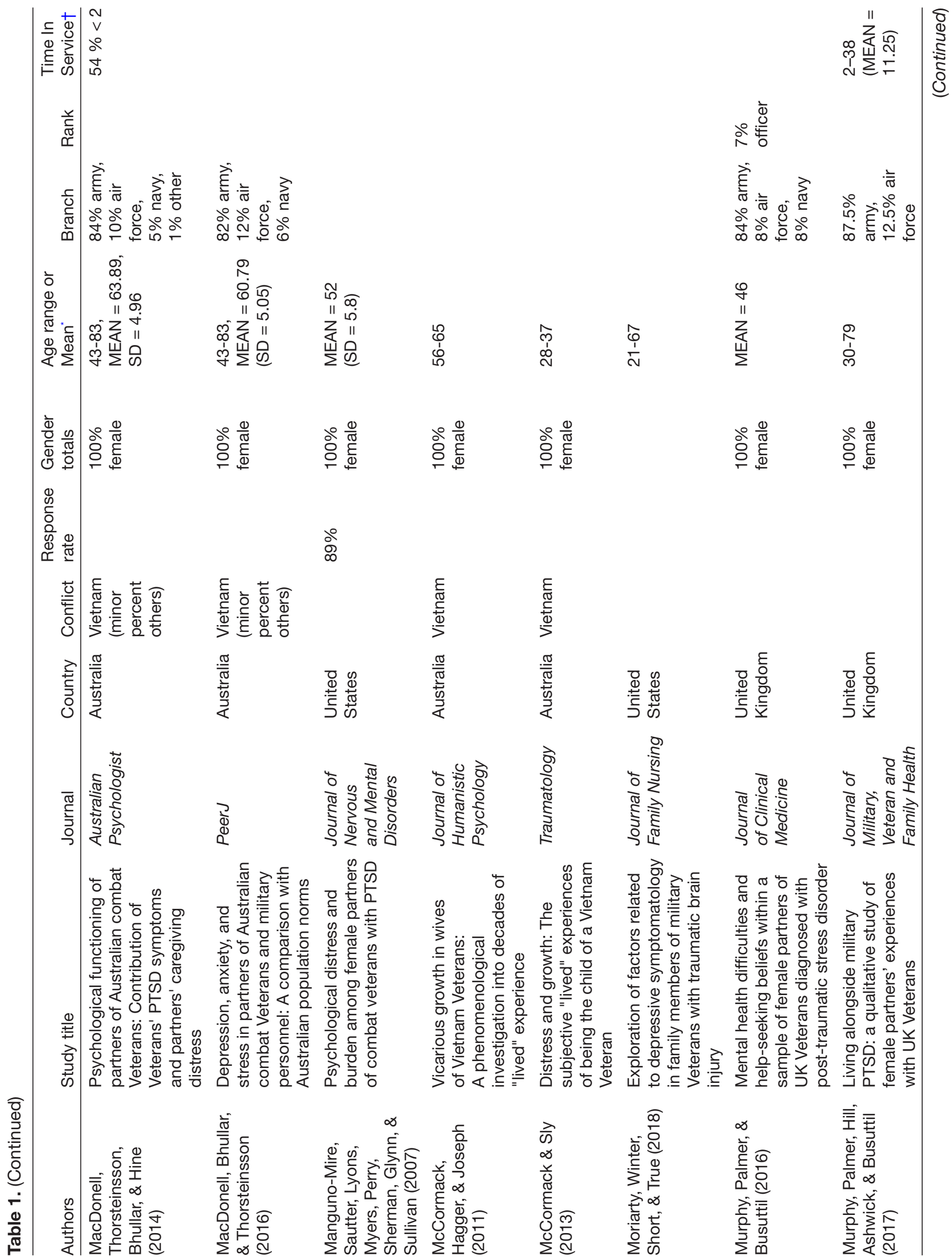




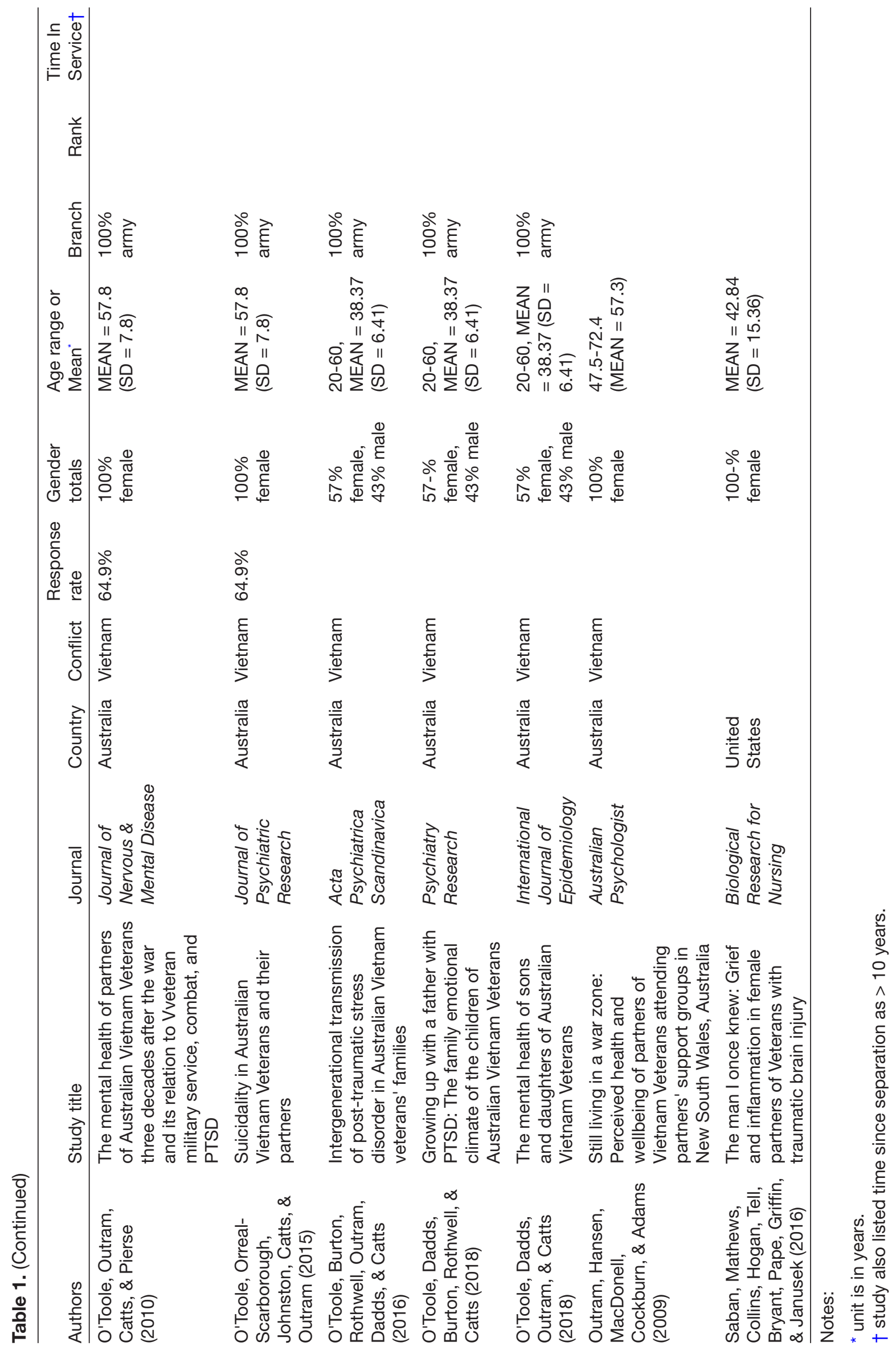


$37 \%$ for generalized anxiety disorder, and $17 \%$ for PTSD symptomology, with the clinical population more likely to report barriers to care, and more likely to associate those barriers with stigmatizing beliefs.

Lee et al. (United States) ${ }^{59}$ examined problem drinking in Veterans and partners, noting the knowledge gap regarding alcohol misuse in separated service members/ partners with a sample comprised of $82 \%$ Veterans and $18 \%$ reservists/civilian-assigned National Guard and their spouses, finding higher levels of drinking behaviour by either member of the couple independently influenced the other's hazardous drinking behaviour.

Four studies described non-significant findings. Alessi et al. (United States) ${ }^{60}$ found higher levels of anxiety and depression in wives of Veterans compared to a married female control but not at a significant level. While Calhoun, Backham, and Bosworth (United States) ${ }^{22}$ found partners caring for Veterans with PTSD experienced higher rates of mental illnesses than partners of non-PTSD Veterans, there was no independent association between Veteran PTSD and partner depression or anxiety. Moriarty et al. (United States) ${ }^{61}$ found depression in Veteran family members significantly higher when caring for a Veteran with PTSD, but there was no significant difference in depression between partners and other family members. Saban et al. (United States) ${ }^{62}$ examined depression as a mediator in the association of grief on inflammation in female partners caring for Veterans with a traumatic brain injury, but depressive symptomology did not mediate the effects of anger/blame on inflammation.

\section{Adult children of Veterans}

Three studies focused on PTSD risk among the adult children of Australian Vietnam Veterans, either because of childhood family emotional climate ${ }^{63}$ or intergenerational transmission of trauma. ${ }^{64-66}$ Gunter et al. (Australia) ${ }^{63}$ found paternal attachment associated with PTSD, anxiety, and depression in adult daughters and maternal attachment associated with PTSD and depression in all offspring, and with anxiety in daughters. O'Toole et al. (Australia) ${ }^{64}$ found Veteran PTSD was associated with PTSD risk in adult children and a gendered effect whereby Veteran depression influenced PTSD risk in males, and Veteran alcohol misuse influenced alcohol misuse in males and PTSD risk in females (but not after controlling for Veteran PTSD). O'Toole et al. (Australia) ${ }^{65}$ included the effect of PTSD on mental health in this population, finding it associated with increased trauma exposure and higher rates of anxiety, depression, alcohol/substance misuse, and PTSD. Veteran PTSD was also strongly associated with the other psychological outcomes in adult children. O'Toole et al. (Australia) ${ }^{66}$ also examined the impact of a Veteran parent with PTSD and family emotional climate on adult children, but from a context of positive/negative attachment impact on adult child distress by PTSD symptom rather than aggregate disorder, finding Veteran PTSD and depression associated with a significant, negative effect on family emotional climate, with daughters particularly affected.

Forrest, Edwards, and Daraganova (Australia) ${ }^{67}$ looked at specific psychopathologies and overall mental health in adult children of deployed Veterans compared to children of non-deployed Veterans, finding higher likelihood of anxiety (OR $=1.54, \mathrm{CI}=1.04,2.28)$, depression $(\mathrm{OR}=1.77, \mathrm{CI}=1.03,3.05)$, and poorer mental health $(\mathrm{B}=-5.08, \mathrm{CI}=-6.60,-3.56)$, in addition to higher likelihood of suicide/self-harm $(\mathrm{OR}=2.39$, $\mathrm{CI}=1.57,3.65)$ and suicidal plan $(\mathrm{OR}=3.52, \mathrm{CI}=1.40$, 8.85) among the former.

One study concerning this population was nonsignificant: Johnson, Vidal, and Lilly (United States) ${ }^{68}$ examined anxiety and depression in a college-aged sample, finding children of Veterans did not differ in anxiety prevalence compared to a normative sample and, while a Veteran parent was positively correlated with child depression, significance was not reached after controlling for child demographic factors.

\section{Meta-synthesis of qualitative findings}

Data collection for qualitative studies $(\mathrm{N}=6$, Table 1$)$ included semi-structured interviews (Australia, United Kingdom), ${ }^{69-71}$ focus groups (Australia, Canada) $)^{72-73}$ and harvesting opportunistic data from an Internet forum (Canada). ${ }^{74}$ These studies focused almost exclusively on partners $(\mathrm{N}=4)$ or the family unit $(\mathrm{N}=1)$ with only one study ${ }^{70}$ describing the experiences of adult children, a sample of three siblings. These studies were largely focused on the experiences of family members as they related to a Veteran with PTSD. Four meta-synthesis themes were identified: personal feelings and internal emotions referencing individual internal thoughts and self-referential emotions, Veteran-oriented focusing exclusively on the Veteran, help and support describing help/support seeking, desires, and barriers, and acting as a unit referring to a shared environ ment, either as a dyad or a family unit (Figure 2; Note: Theme names capitalized at all levels in-text). 


\begin{tabular}{|c|c|c|}
\hline Personal feelings ar & nd internal emotions & Veteran-oriented \\
\hline 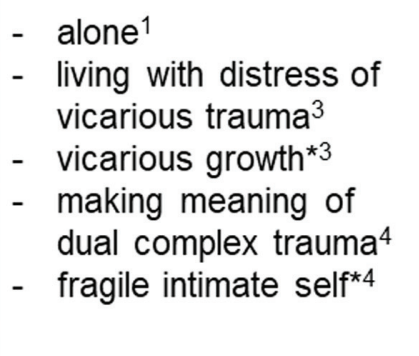 & $\begin{array}{l}\text { - } \text { growthful forgiveness } \\
\text { and self-care }{ }^{* 4} \\
\text { - } \text { physical health } \\
\text { - } \text { mental health }^{6} \\
\text { - } \text { altered sense of self } 6 \\
\text { - } \\
\text { search for } \\
\text { explanation }\end{array}$ & $\begin{array}{l}\text { - } \text { all-consuming effects of the illness }{ }^{1} \\
\text { - } \text { walking on eggshells }{ }^{1} \\
\text { - } \text { ambiguous loss }{ }^{1} \\
\text { - } \text { betrayal and neglect }^{\star 4} \\
\text { - like father, like daughter } \\
\text { - challenges faced } \\
\text { - like living in a war } \text { zone }^{6} \\
\text { - } \text { wife as carer }\end{array}$ \\
\hline \multicolumn{2}{|c|}{ Help \& support } & Acting as a unit \\
\hline \multicolumn{2}{|c|}{$\begin{array}{l}\text { - desired type of support }{ }^{\star 5} \\
\text { - } \text { barriers to support }{ }^{\star 5} \\
\text { - } \text { sources of help: the veteran family }{ }^{6}\end{array}$} & 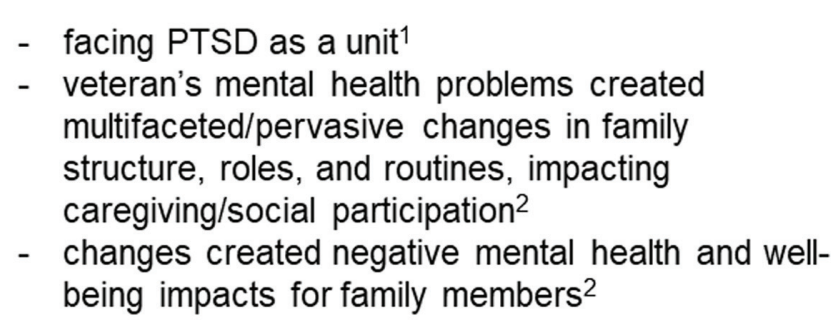 \\
\hline
\end{tabular}

Figure 2. Study themes by meta-synthesis theme

${ }^{1}$ Beks, 2016; ${ }^{2}$ Cramm et al., 2020; ${ }^{3}$ McCormack, Hagger, \& Joseph, 2011; ${ }^{4}$ McCormack \& Sly, 2013; 5 Murphy et al., 2017; ${ }^{6}$ Outram et al., 2009; *includes subordinate themes

\section{Personal feelings and internal emotions}

Partners of Veterans with PTSD described feeling Alone, ${ }^{74}$ isolated from their partner and society, with their physical/mental health adversely impacted by the Veteran's PTSD. They described an Altered Sense of Self defined by loss of self, life experiences, and isolation. ${ }^{72}$ Partners described secondary traumatization as Living with Distress of Vicarious Trauma and reported adapting to how their partner and life had changed. ${ }^{69}$ They referred to this process as a Search for Explanation into their partner's suffering and how they could understand it. ${ }^{72}$ Some partners took meaning from the experience, describing a journey of Vicarious Growth, including describing development of Humble Acceptance, Love, Gratitude, Empathy, and Personal Strength. ${ }^{69}$

The adult children ${ }^{70}$ expressed a similar path with the over-arching theme of Making Meaning of Duel Complex Trauma, encompassing distress of a Fragile Intimate Self, a Weak Sense of Self, Shame and Selfblame, Abusive Adult Relationships, and Burden of Responsibility. Of note, partners and adult children both described the effects of veteran PTSD on their own sense of self; partners phrased this effect as a change to something fundamental to themselves, while the adult children described this effect as a foundational damage to their sense of self that corresponded to lasting consequences. These individuals also explored the experience of healing as Growthful Forgiveness and Self-Care, described by subordinate themes of Meaning Making and Acceptance, Forgiveness, Rejecting Rejection, and Doing It Differently. ${ }^{70}$

\section{Veteran-Oriented focus}

Partners described the effects of PTSD on their relationships with their Veteran partners, explaining how the overwhelming impact of caring for their partners and managing other aspects of life stemmed from the All-consuming Effects of the Illness, ${ }^{74}$ and led to feeling Ambiguous Loss regarding the Veteran's former self ${ }^{74}$ and the unwelcome feelings of burden the changing role to a Wife as Carer could generate. ${ }^{72}$ Unpredictable and volatile behaviour among Veterans was reported to create an environment of tension and fear, described as Walking on Eggshell ${ }^{74}$ and Like Living in a War Zone. ${ }^{72}$ The Challenges Faced in these relationships were described by some partners as leading to Inequality in Relationship, Loss of Congruence with Own Identity, Volatile Environment, and Emotional Distress and Isolation. ${ }^{71}$ 
Adult children explained the negative impact on childhood with a Veteran parent, feeling Betrayal and Neglect, assessing themselves as unworthy of their father's attention/affection while he was perceived to vacillate between neglectful absence (Absent Father), abuse (Not Good Enough), and attempts to be a good father (Good Dad/Bad Dad). They described their own secondary traumatization as Like Father, Like Daughter, including Self-Medication, Learning to Be on Alert, and being Denied the Right to Feel, ${ }^{70}$ conveying their perception that their childhood had recreated them in the image of their father.

\section{Help and support}

This theme was identified from two studies, both focused on partners. In Murphy et al. (United Kingdom), ${ }^{71}$ partners described their Desired Type of Support, which included Practical Focus on Improving, Sharing with Fellow Experts, and Care Tailored to the Partner. Barriers to Support included Feeling Restricted by Practical Barriers and Ambivalence About Involvement of Others. The value of applicable support was highlighted in Outram et al. (Australia), ${ }^{72}$ where the theme Sources of Help: The Veteran Family was identified as partners explained the connection and relief they felt when talking to others from within the military community in the same situation.

\section{Acting as a unit}

Facing PTSD as a Unit was identified as a theme encapsulating the partner's commitment to the Veteran and the relationship, externalizing PTSD as a "third entity" to be fought. ${ }^{74(\text { p. 9) }}$ Cramm et al. (Canada) ${ }^{73}$ focused on the family unit, with participants reporting that "Veteran's mental health problems created multifaceted changes in family structure, roles, and routines, impacting caregiving/social participation," ${ }^{\text {73(p. 4) }}$ conceptualizing the impact on a systemic level with multiple individuals affected in multiple ways. These "changes created negative mental health and well-being impacts for family members"73(p. 4) by reciprocal processes between the Veteran, the individual, and the family unit. This theme was present in both partner- and adult-child-focused studies. ${ }^{73-74}$

\section{DISCUSSION}

This review was conducted to highlight and potentially fill extant gaps in literature concerning the mental health outcomes of partners and adult children of ex-service members in Five Eyes alliance countries.
Ultimately, only 24 studies met the inclusion criteria, exposing the under-representation of this population in previous research, but also flagging the potential for future studies.

Half of the studies reviewed $(\mathrm{N}=12)$ were Australian and all focused on family members of Vietnam Veterans, specifically the relationships between Veteran PTSD and mental health outcomes in partners ${ }^{53,55,56,69,72}$ /adult children, ${ }^{57,63-67,70}$ with the quantitative studies examining the prevalence of psychopathologies in these populations compared to other military sub-groups and national prevalence rates. Qualitative studies were very much family focused, exploring the experience of living with a Veteran's PTSD and effects on the entire family, both positive and negative. Findings indicated higher rates of difficulties in partners/ adult children as a function of the Veteran's PTSD as compared to national prevalence rates and/or other subgroups, with family-centric adaptation and support described in the qualitative findings.

All U.S. studies $(\mathrm{N}=8)$ were quantitative, all but one focused on the partner, and five featured nonsignificant minor/main results. ${ }^{22,60-62,68}$ The remaining three studies examined the association between Veteran PTSD and partner distress, ${ }^{52,54}$ and reciprocal hazardous drinking in a Veteran/partner dyad. ${ }^{59}$ The U.S. findings reinforced the relationship between Veteran PTSD/mental health issues and partner distress/psychopathology, centring on the effects of PTSD and secondary trauma on the couple from both psychological and practical viewpoints. It is worth noting that only two U.S. studies used a Vietnam Veteran cohort versus 12 Australian studies despite a Vietnam involvement of approximately 2.7 million troops compared to Australia's 50,000; $;^{75-76}$ this contrast may be due to differing cultural views of the Vietnam conflict.

The Canadian studies $(\mathrm{N}=2)$ were qualitative explorations of partner ${ }^{74}$ and family unit ${ }^{73}$ experience of the Veteran's PTSD. While partners described negative impacts on their mental health (themes Alone, Ambiguous Loss, and All-consuming Effects of the illness ${ }^{74}$ ), there was the uplifting Facing PTSD as a Unit, ${ }^{74}$ and, while family members reported adverse effects on their mental health and well-being, there were also changes made in the family structure as a result of/reaction to the Veteran's PTSD. ${ }^{73}$

The UK studies $(\mathrm{N}=2)$ both investigated intimate partners, mental health, and perceived barriers to care for both themselves and the Veteran with PTSD. 
Murphy et al. (United Kingdom) ${ }^{58}$ found large percentages of the study population met clinical thresholds for alcohol misuse (45\%), depression (39\%), generalized anxiety disorder (37\%), and PTSD (17\%), with this clinical sub-group perceiving more barriers and more stigmatic associations. In the qualitative study, partners expressed challenges due to Veteran PTSD (Inequality in Relationship, Loss of Congruence with Own Identity, Volatile Environment, and Emotional Distress and Isolation ${ }^{71}$ ) but were hopeful and positive when discussing optimal support and care (Practical Focus on Improving, Sharing with Fellow Experts, and Care Tailored to the Partner ${ }^{71}$ ), with fewer perceived barriers.

Veteran PTSD and symptomology were particularly prominent in the literature, reflecting the seriousness of the issue, but also potentially due to publishing bias and researcher focus. Clinically sourced samples represent only help-seeking sub-groups, and a focus on PTSD neglects other psychopathologies, ${ }^{77}$ leading to a constant refocusing of Veteran family issues through the lens of PTSD, whether it is present in individual lives or not. This review had multiple stated outcomes for exploration; however, as the abundance of Veteran family research concerned PTSD, the findings reflect the impact of PTSD but do not accurately describe a representative experience of Veteran families in Five Eyes countries. Importantly, a majority of Veterans do not experience psychological consequences of service, ${ }^{78}$ with personal risk associated with trauma/injury, ${ }^{79}$ which in turn have the potential to affect family members.

\section{Strengths and limitations}

The results of this review must be taken considering its limitations. While inclusion criteria defined Veterans as ex-service members, this term was used broadly and inconsistently in the literature, mirroring the differences in this definition across countries of the Five Eyes alliance and reflecting differing cultural views of both the military as an institution and individual service members. The United Kingdom favours an inclusive definition, while the United States prioritizes length and details of service, and Australia applies the term only to those who have served overseas. ${ }^{80}$

While all results presented pertained to Five Eyes alliance countries, differences in demographic, cultural, and psychosocial variables prevent generalization to a higher population level. Several findings showed effects that fell below statistical significance or did not survive controls/association analysis; however, the distress suffered by the partners and adult children should not be discounted. Though these studies examined the same outcome in similar populations, they used differing measures, main outcomes, and context, damaging the validity of direct comparisons or a true quantitative meta-analysis.

Qualitative data from the included studies illustrated partner and adult child distress and personal hardship where quantitative measures could not. Grey literature was cited here but was not included in the review as the materials were not peer reviewed. It must be noted that there are peer-reviewed, validated, grey literature sources available to researchers, including military/ government data.

The strengths of this review include a rigorous methodology that included protocol registry and strict adherence to Cochrane standards for the performance of a systematic review. It has also starkly illuminated the breadth of the current research into the psychological health and well-being of partners and adult children of Veterans while also highlighting how little is known about these populations.

\section{Limitations of the included research}

The results described in this project must be taken when also considering the limitations of the background research; this is because the scope of the findings were limited by the paucity of the literature. The narrow field of study of this review impacted results as a majority of the studies investigating psychological outcomes in the children of Veterans used samples $<18$ years and a majority of the studies examining these outcomes in the partners of Veterans concentrated on active duty samples, none of which could be included here due to this study's inclusion/exclusion criteria.

Of the 24 studies reviewed here, 17 featured recruitment through the Veteran while only 6 recruited directly (1 utilized opportunistic secondary data). Most of the available literature was focused on Veteran PTSD, neglecting the experiences of military Veteran families who are not dealing with PTSD or any other mental illness. Additionally, there is a sizable body of research exploring active duty deployment and re-integration in the military family but substantially less on the transition to civilian life and outcomes thereafter.

Several additional objectives were outlined in the review protocol for investigation in this review, including identifying risk/resilience factors and their prevalence, studies linking family member outcomes to those of the ex-service member, and differences in cross-country 
results, risk/resilience factors between partners and children, early-service-leaver families, branch of military service, and between children born during their parent's military service and post-service. Unfortunately, these objectives were not able to be fulfilled due to lack of relevant data in the included studies and lack of included studies relevant to these objectives, which again underscores the need for additional research into these issues.

\section{Implications and future research}

The implications of this review are three-fold: 1) there is insufficient research into the mental health and well-being outcomes of the partners and adult children of ex-service members, 2) the extant research has shown a clear association of Veteran PTSD and adverse outcomes in this population and, 3) the barriers to support act as a unique hardship for individuals and family units who are under stress. Additional research is urgently needed to explore not only mental health outcomes in Veteran families, but also to investigate factors associated with resilience and well-being. There is a large population of adult children of Vietnam Veterans within the Five Eyes countries and the only qualitative research describing their experiences was limited to a single Australian study of one family.

Most of the research discussed in this review focused on Veterans with PTSD, excluding other mental illnesses but also ignoring the fact that many Veterans do not suffer from mental illness. ${ }^{81-85}$ The mental health and well-being of partners and adult children of these Veterans is important and future research must concentrate on all sub-groups within this population to adequately serve it. Research into successful help/support factors would also be invaluable in conjunction with these future studies in designing programs, interventions, and other venues of support. Initiatives which start when the service member and family transition to civilian life would support and protect this population while also strengthening the entire military community throughout Five Eyes alliance countries.

To conclude, a sub-group of adult children and partners of Veterans may face unique mental ill health risks dependent on individual factors but associated with Veteran PTSD. This review stands as a barometer of the situation in the Five Eyes alliance countries based on previous research, with further research into Veteran family experiences needed. It is clear that the effects of military service on Veterans and their families can persist into civilian life, necessitating an increased focus on the care available and provided to this population.

\section{REFERENCES}

1. Fear NT, Jones M, Murphy D, et al. What are the consequences of deployment to Iraq and Afghanistan on the mental health of the UK armed forces? A cohort study. Lancet. 2010 May 22;375(9728):1783-97. https://doi.org/10.1016/s0140-6736(10)60672-1

2. Armour C, Contractor A, Elhai JD, et al. Identifying latent profiles of posttraumatic stress and major depression symptoms in Canadian Veterans: exploring differences across profiles in health related functioning. Psychiatry Res. 2015 Jul 30;228(1):17. https://doi.org/10.1016/j.psychres.2015.03.011. Medline:25936834

3. Warner CH, Appenzeller GN, Warner C, et al. Psychological effects of deployments on military families. Psychiatr Ann. 2009;39(2):56-63. https://doi. org/10.3928/00485713-20090201-11

4. Dekel R, Monson CM. Military-related post-traumatic stress disorder and family relations: current knowledge and future directions. Aggress Violent Behav. 2010 Mar;15(4):303-9. https://doi.org/10.1016/j. avb.2010.03.001

5. Diehle J, Brooks SK, Greenberg N. Veterans are not the only ones suffering from posttraumatic stress symptoms: what do we know about dependents' secondary traumatic stress? Soc Psychiatry Psychiatr Epidemiol. 2017 Jan;52(1):35-44.

6. Gribble R, Goodwin L, Fear NT. Mental health outcomes and alcohol consumption among UK military spouses/partners: A comparison with women in the general population. Eur J Psychotraumatol. 2019 Sep 23;10(1):1654781. https://doi.org/10.1080/2000 8198.2019.1654781. Medline:31632615

7. Dekel R, Solomon Z. Secondary traumatization among wives of Israeli POWs: The role of POWs' distress. Soc Psychiatry Psychiatr Epidemiol. 2006 Jan;41(1):2733. https://doi.org/10.1007/s00127-005-0002-6. Medline: 16341620

8. Dekel R, Goldblatt H. Is there intergenerational transmission of trauma? The case of combat Veterans' children. Am J Orthopsychiatry. 2008 Jul;78(3):281-9. https://doi.org/10.1037/a0013955. Medline: 19123747

9. Cozza SJ, Chun RS, Polo JA. Military families and children during Operation Iraqi Freedom. Psychiatr Q. 2005 Winter;76(4):371-8. https://doi.org/10.1007/ s11126-005-4973-y. Medline: 16217632

10. Chartrand MM, Frank DA, White LF, et al. Effect of parents' wartime deployment on the behavior of young children in military families. Arch Pediatr Adolesc Med. 2008 Nov;162(11):1009-14. https://doi.org/10.1001/ archpedi.162.11.1009. Medline:18981347

11. Gribble R, Mahar AL, Keeling M, et al. Are we family? A scoping review of how military families are defined in 
mental health and substance use research. J Mil Veteran Fam Health. 2020 Aug;6(2):85-119. https://doi. org/10.3138/jmvfh-2019-0054

12. Osofsky JD, Chartrand MM. Military children from birth to five years. Future Child. 2013 Fall;23(2):6177. https://doi.org/10.1353/foc.2013.0011. Medline:25518692

13. Flake EM, Davis BE, Johnson PL, et al. The psychosocial effects of deployment on military children. J Dev Behav Pediatr. 2009 Aug;30(4):271-8. https://doi.org/10. 1097/dbp.0b013e3181aac6e4. Medline: 19606059

14. Lester P, Peterson K, Reeves J, et al. The long war and parental combat deployment: effects on military children and at-home spouses. J Am Acad Child Adolesc Psychiatry. 2010 Apr;49(4):310-20. https:// doi.org/10.1016/j.jaac.2010.01.003

15. Cramm H, McColl MA, Aiken AB, et al. The mental health of military-connected children: a scoping review. J Child Fam Stud. 2019 Apr;28(7):1725-35. https:// doi.org/10.1007/s10826-019-01402-y

16. International Institute for Strategic Studies. The military balance 2019. London: Routledge; 2019.

17. Department of Defence. 2018 demographics profile active military families; 2018. Available from: https:// download.militaryonesource.mil/12038/MOS/ Infographic/2018-demographics-active-duty-families. pdf

18. Manser L. Profile of military families in Canada: 2017 regular force demographics. Ottawa (ON): Canadian Forces Morale and Welfare Services; 2018.

19. Greene-Shortridge TM, Britt TW, Castro CA. The sigma of mental health problems in the military. Mil Med. 2007 Feb;172(2):157-61. https://doi. org/10.7205/milmed.172.2.157. Medline: 17357770

20. Yambo T, Johnson M. An integrative review of the mental health of partners of Veterans with combatrelated posttraumatic stress disorder. J Am Psychiatr Nurses Assoc. 2014 Jan-Feb;20(1):31-41. https://doi. org/10.1177/1078390313516998. Medline:24441511

21. Beckham JC, Lytle BL, Feldman ME. Caregiver burden in partners of Vietnam War Veterans with posttraumatic stress disorder. J Consult Clin Psychol. 1996 Oct;64(5):1068-72. https://doi. org/10.1037/0022-006x.64.5.1068

22. Calhoun PS, Beckham JC, Bosworth HB. Caregiver burden and psychological distress in partners of Veterans with chronic posttraumatic stress disorder. J Trauma Stress. 2002 Jun;15(3):205-12. https://doi. org/10.1023/a:1015251210928

23. Dekel R, Solomon Z, Bleich A. Emotional distress and marital adjustment of caregivers: Contribution of level of impairment and appraised burden. Anxiety Stress Coping. 2007 Jan;18(1):71-82. https://doi. org/10.1080/10615800412336427
24. Thandi G, Harden L, Cole L, et al. Systematic review of caregiver burden in spouses and partners providing informal care to wounded, injured or sick (WIS) military personnel. J R Army Med Corps. 2018 Sep;164(5):365-9. https://doi.org/10.1136/ jramc-2017-000821. Medline:29440468

25. Eaton KM, Hoge CW, Messer SC, et al. Prevalence of mental health problems, treatment need, and barriers to care among primary care-seeking spouses of military service members involved in Iraq and Afghanistan deployments. Mil Med. 2008 Nov;173(11):10516. https://doi.org/10.7205/milmed.173.11.1051. Medline: 19055177

26. Verdeli H, Baily C, Vousoura E, et al. The case for treating depression in military spouses. J Fam Psychol. 2011 Aug;25(4):488-96. https://doi.org/10.1037/ a0024525. Medline:21842994

27. Donoho CJ, LeardMann C, O'Malley CA, et al. Depression among military spouses: Demographic, military, and service member psychological health risk factors. Depress Anxiety. 2018 Dec;35(12):1137-44. https://doi.org/10.1002/da.22820. Medline:30103266

28. Ahmadi H, Green SL. Screening, brief intervention, and referral to treatment for military spouses experiencing alcohol and substance use disorders: A literature review. J Clin Psychol Med Settings. 2011 Jun;18(2):129-36. https://doi.org/10.1007/s10880011-9234-7. Medline:21626357

29. Gribble R, Thandi GK, Goodwin L, et al. Hazardous alcohol consumption among spouses or partners of military service personnel: A systematic review of the literature. J R Army Med Corps. 2018 Sep;164(5):3808. https://doi.org/10.1136/jramc-2017-000845. Medline:29326125

30. Green S, Nurius PS, Lester P. Spouse psychological wellbeing: A keystone to military family health.J Hum Behav Soc Environ. 2013 Jan 1;23(6):753-68. https://doi.org/ 10.1080/10911359.2013.795068. Medline:24415897

31. Ben-Zeev D, Corrigan PW, Britt TW, et al. Stigma of mental illness and service use in the military. J Ment Health. 2012 Jun;21(3):264-73. https://doi.org/10.31 09/09638237.2011.621468. Medline:22250849

32. de Burgh HT, White CJ, Fear NT, et al. The impact of deployment to Iraq or Afghanistan on partners and wives of military personnel. Int Rev Psychiatry. 2011 Apr;23(2):192-200. https://doi.org/10.3109/0954026 1.2011.560144. Medline:21521089

33. Barker LH, Berry KD. Developmental issues impacting military families with young children during single and multiple deployments. Mil Med. 2009 Oct:174(10):1033-40. https://doi.org/10.7205/ milmed-d-04-1108. Medline:19891214

34. Gorman GH, Eide M, Hisle-Gorman E. Wartime military deployment and increased pediatric mental 
and behavioral health complaints. Pediatrics. 2010 Dec;126(6):1058-66. https://doi.org/10.1542/ peds.2009-2856. Medline:21059715

35. Trautmann J, Alhusen J, Gross D. Impact of deployment on military families with young children: A systematic review. Nurs Outlook. 2015 Nov-Dec;63(6):65679. https://doi.org/10.1016/j.outlook.2015.06.002. Medline:26183660

36. Cederbaum JA, Gilreath TD, Benbenishty R, et al. Well-being and suicidal ideation of secondary school students from military families. J Adolesc Health. 2014 Jun;54(6):672-7. https://doi.org/10.1016/j. jadohealth.2013.09.006. Medline:24257031

37. Lucier-Greer M, O’Neal CW, Arnold AL, et al. Adolescent mental health and academic functioning: Empirical support for contrasting models of risk and vulnerability. Mil Med. 2014 Nov;179(11):127987. https://doi.org/10.7205/milmed-d-14-00090. Medline:25373055

38. Lucier-Greer M, Arnold AL, Grimsley RN, et al. Parental military service and adolescent well-being: Mental health, social connections and coping among youth in the USA. Child Fam Soc Work. 2014 Jun;21(4):421-32. https://doi.org/10.1111/cfs.12158

39. Yablonsky AM, Barbero ED, Richardson JW. Hard is normal: Military families' transitions within the process of deployment. Res Nurs Health. 2016 Feb;39(1):42-56. https://doi.org/10.1002/nur.21701. Medline:26595761

40. Kritikos TK, Comer JS, He M, et al. Combat experience and posttraumatic stress symptoms among military-serving parents: A meta-analytic examination of associated offspring and family outcomes. J Abnorm Child Psychol. 2019 Jan;47(1):131-48. https://doi. org/10.1007/s10802-018-0427-5. Medline:29687429

41. King N, Smith A. Exploring the impact of parental post-traumatic stress disorder on military family children: A review of the literature. Nurse Educ Today. 2016 Dec;47:29-36. https://doi.org/10.1016/j. nedt.2016.04.018. Medline:27189880

42. Aromataris E, Munn Z. Chapter 1: JBI systematic reviews. In: Aromataris E, Munn Z, editors. JBI manual for evidence synthesis; 2020. Available from: https:// synthesismanual.jbi.global

43. National Institutes of Health. Quality assessment tool for observational cohort and cross-sectional studies; 2014 [cited 2020 Dec 16]. Available from: https:// www.nhlbi.nih.gov/health-pro/guidelines/in-develop/ cardiovascular-risk-reduction/tools/cohort

44. Popay J, Roberts H, Sowden A, et al. Guidance on the conduct of narrative synthesis in systematic reviews. In: A product from the ESRC methods programme version. Vol. 1. Bailrigg (UK): Lancaster University; 2006. p. 11-12.
45. Snilstveit B, Oliver S, Vojtkova M. Narrative approaches to systematic review and synthesis of evidence for international development policy and practice. J Dev Effect. 2012 Sept;4(3):409-29. https://doi.org/10. 1080/19439342.2012.710641

46. Mays N, Pope C, Popay J. Systematically reviewing qualitative and quantitative evidence to inform management and policy-making in the health field. J Health Serv Res Policy. 2005 Jul;10(Suppl 1):620. https://doi.org/10.1258/1355819054308576. Medline: 16053580

47. Rodgers M, Sowden A, Petticrew M, et al. Testing methodological guidance on the conduct of narrative synthesis in systematic reviews. Evaluation. 2009 Jan; 15(1):49-74. https://doi.org/10.1177/1356389 008097871

48. Lucas PJ, Baird J, Arai L, et al. Worked examples of alternative methods for the synthesis of qualitative and quantitative research in systematic reviews. BMC Med Res Methodol. 2007 Jan 15;7(1):4. https://doi. org/10.1186/1471-2288-7-4. Medline:17224044

49. Elliott R, Timulak L. Descriptive and interpretive approaches to qualitative research. In: Miles J, Gilbert P, editors. A handbook of research methods in clinical and health psychology. Oxford (UK): Oxford University Press; 2005. p. 147-59.

50. Timulak L. Meta-analysis of qualitative studies: A tool for reviewing qualitative research findings in psychotherapy. Psychother Res. 2009 Jul;19(4-5):591600. https://doi.org/10.1080/10503300802477989. Medline: 19034804

51. Levitt HM. How to conduct a qualitative metaanalysis: tailoring methods to enhance methodological integrity. Psychother Res. 2018 May;28(3):367-78. https://doi.org/10.1080/10503307.2018.1447708. Medline:29533169

52. Campbell SB, Renshaw KD. Distress in spouses of Vietnam Veterans: Associations with communication about deployment experiences. J Fam Psychol. 2012 Feb;26(1):18-25. https://doi.org/10.1037/a0026680. Medline:22182339

53. MacDonell GV, Thorsteinsson EB, Bhullar N, et al. Psychological functioning of partners of Australian combat Veterans: Contribution of Veterans' PTSD symptoms and partners' caregiving distress. Aust Psychol. 2014 Jun;49(5):305-12. https://doi. org/10.1111/ap.12069

54. Manguno-Mire G, Sautter F, Lyons J, et al. Psychological distress and burden among female partners of combat Veterans with PTSD. J Nerv Ment Dis. 2007 Feb;195(2):144-51. https://doi.org/10.1097/01. nmd.0000254755.53549.69. Medline: 17299302

55. MacDonell GV, Bhullar N, Thorsteinsson EB. Depression, anxiety, and stress in partners of Australian 
combat Veterans and military personnel: A comparison with Australian population norms. Peer J. 2016 Aug 25;4:e2373. https://doi.org/10.7717/peerj.2373. Medline:27635339

56. O'Toole BI, Outram S, Catts SV, et al. The mental health of partners of Australian Vietnam Veterans three decades after the war and its relation to Veteran military service, combat, and PTSD. J Nerv Ment Dis. 2010 Nov;198(11):841-5. https://doi.org/10.1097/ nmd.0b013e3181f98037. Medline:21048477

57. O'Toole BI, Orreal-Scarborough T, Johnston D, et al. Suicidality in Australian Vietnam Veterans and their partners. J Psychiatr Res. 2015 Jun;65:30-6. https://doi.org/10.1016/j.jpsychires.2015.02.003. Medline:25914085

58. Murphy D, Palmer E, Busuttil W. Mental health difficulties and help-seeking beliefs within a sample of female partners of UK Veterans diagnosed with post-traumatic stress disorder. J Clin Med. 2016 Aug 1;5(8):68. https://doi.org/10.3390/jcm5080068. Medline:27490576

59. Lee JD, O’Neill AM, Denning EC, et al. A dyadic examination of drinking behaviors within militaryconnected couples. Mil Behav Health. 2020 Oct 14;8(4):396-409. https://doi.org/10.1080/21635781.2 020.1825241

60. Alessi MW, Ray JW, Ray GE, et al. Personality and psychopathology profiles of Veterans' wives: measuring distress using the MMPI-2. J Clin Psychol. 2001 Dec;57(12):1535--. https://doi.org/10.1002/ jclp.1115. Medline:11745594

61. Moriarty H, Winter L, Short TH, et al. Exploration of factors related to depressive symptomatology in family members of military Veterans with traumatic brain injury. J Fam Nurs. 2018 May;24(2):184-216. https://doi.org/10.1177/1074840718773470. Medline:30101651

62. Saban KL, Mathews HL, Collins EG, et al. The man I once knew: Grief and inflammation in female partners of Veterans with traumatic brain injury. Biol Res Nurs. 2016 Jan; 18(1):50-9. https://doi. org/10.1177/1099800414568661. Medline:25636402

63. Gunter HN, O’Toole BI, Dadds M, et al. Family emotional climate in childhood and risk of PTSD in adult children of Australian Vietnam Veterans. Psychiatry Res. 2020 Dec;294:113509. https://doi.org/10.1016/j.psychres.2020.113509. Medline:33075652

64. O'Toole BI, Burton MJ, Rothwell A, et al. Intergenerational transmission of post-traumatic stress disorder in Australian Vietnam Veterans' families. Acta Psychiatr Scand. 2017 May;135(5):36372. https://doi.org/10.1111/acps.12685. Medline:28032331
65. O'Toole BI, Dadds M, Outram S, et al. The mental health of sons and daughters of Australian Vietnam Veterans. Int J Epidemiol. 2018 Aug 1;47(4):1051-9. https://doi.org/10.1093/ije/dyy010. Medline:29425292

66. O'Toole BI, Dadds M, Burton MJ, et al. Growing up with a father with PTSD: The family emotional climate of the children of Australian Vietnam Veterans. Psychiatry Res. 2018 Oct;268:175-83. https://doi.org/10.1016/j.psychres.2018.06.071. Medline:30031270

67. Forrest W, Edwards B, Daraganova G. The intergenerational consequences of war: Anxiety, depression, suicidality, and mental health among the children of war Veterans. Int J Epidemiol. 2018 Aug 1;47(4):1060-7. https://doi.org/10.1093/ije/dyy040. Medline:29590363

68. Johnson NH, Vidal C, Lilly FR. Absence of a link between childhood parental military service on depression and anxiety disorders among college students. Mil Med. 2018 Sep 1;183(9-10):e5028. https://doi.org/10.1093/milmed/usy003. Medline:29547979

69. McCormack L, Hagger MS, Joseph S. Vicarious growth in wives of Vietnam Veterans. J Humanist Psychol. 2010 Aug 2;51(3):273-90. https://doi. org/10.1177/0022167810377506

70. McCormack L, Sly R. Distress and growth: the subjective "lived" experiences of being the child of a Vietnam Veteran. Traumatology. 2013 May 21;19(4): 303-12. https://doi.org/10.1177/1534765613481855

71. Murphy D, Palmer E, Hill K, et al. Living alongside military PTSD: A qualitative study of female partners' experiences with UK Veterans. J Mil Veteran Fam Health. 2017 Apr 4;3(1):52-61. https://doi. org $/ 10.3138 /$ jmvfh. 4011

72. Outram S, Hansen V, MacDonell G, et al. Still living in a war zone: Perceived health and well-being of partners of Vietnam Veterans attending partners' support groups in New South Wales, Australia. Aust Psychol. 2009 Aug;44(2):128-35.

73. Cramm H, Norris D, Schwartz KD, et al. Impact of Canadian armed forces Veterans' mental health problems on the family during the military to civilian transition. Mil Behav Health. 2019 Aug 12;8(2):148-58.

74. Beks TA. Walking on eggshells: The lived experience of partners of Veterans with PTSD. Qual Rap. 2016 Apr 10;21:645-60.

75. U.S. Department of Veteran Affairs. Military health history pocket card for health professions trainees and clinicians; 2019. Available from: https://www.va.gov/ oaa/pocketcard/vietnam.asp

76. Returned and Services League of Australia (New South Wales Branch). The Vietnam war; 2021. Available from: 
https://www.rslnsw.org.au/commemoration/australiasmilitary-heritage/the-vietnam-war/

77. Oster C, Morello A, Venning A, et al. The health and well-being needs of Veterans: A rapid review. BMC Psychiatry. 2017 Dec 29;17(1):414. https://doi. org/10.1186/s12888-017-1547-0. Medline:29284431

78. Pemberton MR, Forman-Hoffman VL, Lipari RN, et al. Prevalence of past year substance use and mental illness by Veteran status in a nationally representative sample. SAMHSA; 2016 Nov. Available from: https://www.samhsa.gov/data/sites/default/files/ NSDUH-DR-VeteranTrends-2016/NSDUH-DRVeteranTrends-2016.htm

79. Spikol E, Ross J, McGlinchey E, et al. Identifying service-related predictors of community reintegration difficulties in Northern Irish military Veterans. [preprint] DOI: 10.31219/osf.io/ckvpx

80. Dandeker C, Wessely S, Iversen A, et al. What's in a name? Defining and caring for "Veterans." Armed Forces Soc. 2006 Jan 1;32(2):161-77. https://doi. org/10.1177/0095327x05279177

81. Zamorski MA, Bennett RE, Rusu C, et al. Prevalence of past-year mental disorders in the Canadian armed forces, 2002-2013. Can J Psychiatry. 2016 Apr;61(1 Suppl):26S-35S. https://doi. org/10.1177/0706743716628854. Medline:27270739

82. Deployment Health Clinical Center. Mental health disorder prevalence among active duty service members in the military health system, fiscal years 2005-2016; 2017. Available from: https://www.pdhealth.mil/ sites/default/files/images/mental-health-disorderprevalence-among-active-duty-service-members508.pdf

83. Gibb S, Cunningham R. Mental health and addiction in Aotearoa, New Zealand: Recent trends in service use, unmet need, and information gaps; 2018. Available from: https://www.mentalhealth.inquiry.govt.nz/ assets/Summary-reports/Otago-mental-health.pdf

84. Van Hooff M, Lawrence-Wood E, Hodson S, et al. Mental health prevalence, mental health and well-being transition study. Canberra: The Department of Defence and the Department of Veterans' Affairs; 2018.

85. Ministry of Defence. UK armed forces mental health: Annual summary and trends over time, 2007/082018/19; 2019. Available from: https://assets. publishing.service.gov.uk/government/uploads/system/ uploads/attachment_data/file/993208/20210617_ MH_Annual_Report_2020-21.pdf

\section{AUTHOR INFORMATION}

Cherie Armour, PhD, is Professor of Psychological Trauma and Mental Health at Queen's University Belfast and the Director of the Research Centre for Stress Trauma and
Related Conditions (STARC). She has held the position of President of the UK Psychological Trauma Society, is an elected board member for the International Society of Traumatic Stress Studies, and an Associate Editor for the European Journal of Psychotraumatology. Currently, Armour is the joint Principal Investigator of the UK Veterans Family Study (UKVFS).

Eric Spikol, PhD, is working as a Research Fellow at the Stress Trauma and Related Conditions (STARC) Research Lab at Queen's University Belfast. An early-career researcher, he is an Associate Fellow of Higher Education with an interest in large-population mental health, psychosis, and behavioural epigenetics. Spikol is currently on the research teams for the UK Veterans Family Study (UKVFS) and the PTSD Experimental Treatment Trial (PETT).

Emily McGlinchey, $\mathrm{PhD}$, is currently working as a research fellow at the Stress Trauma and Related Conditions (STARC) research lab, based in the Psychology Department of Queen's University Belfast (QUB). McGlinchey is also a BPS-accredited Low-Intensity CBT (LI-CBT) therapist with over three years of clinical experience working across a range of both statutory and non-statuary mental health services. McGlinchey is currently involved in several highprofile mental health research projects based at QUB.

Rachael Gribble, $\mathrm{PhD}$, is a lecturer in war \& psychiatry at King's College London (KCL). She joined KCL in 2012 following an MSc in public health at the London School of Hygiene and Tropical Medicine. Her work focuses on military families, women's health, and public attitudes to the military. Her recent work has focused on the mental health and well-being of UK women with a partner in the UK Armed Forces and explored non-operational family separations among naval families.

Nicola T. Fear, $\mathrm{PhD}$, joined the academic department of Military Mental Health at King's College London (KCL) in 2004 having trained as an epidemiologist at the London School of Hygiene and Tropical Medicine and University of Oxford. Fear has also worked as an epidemiologist within the UK Ministry of Defence. Since 2011, she has been Director of the King's Centre of Military Health Research (KCMHR) alongside Professor Sir Simon Wessely. In 2014, Fear was awarded a Chair in Epidemiology.

Dominic Murphy, $\mathrm{PhD}$, is an academic clinical psychologist and has published extensively within the field of trauma and military mental health. He has worked within the field of military mental health since 2003. First, at King's College London (KCL) and then since 2003, Murphy has worked at Combat Stress where he established and runs a research department co-located between Combat Stress and KCL. In 2020, he became President of the UK Psychological Trauma Society. 


\section{COMPETING INTERESTS}

Nicola T. Fear is funded by a grant from the UK Ministry of Defence (MoD) and works on projects funded by the $\mathrm{MoD}$ and Office for Veterans' Affairs. She is also a trustee of a charity supporting Veterans and their families. Dominic Murphy is a trustee for the Forces in Mind Trust.

\section{CONTRIBUTORS}

Conceptualization: C Armour, E Spikol, E McGlinchey, R Gribble, NT Fear, and D Murphy

Methodology: C Armour, E Spikol, E McGlinchey, R Gribble, and NT Fear

Validation: C Armour, E Spikol, andE McGlinchey

Formal Analysis: C Armour, E Spikol, and E McGlinchey

Investigation: E Spikol and E McGlinchey

Data Curation: E Spikol and E McGlinchey

Writing - Original Draft: C Armour, E Spikol, E McGlinchey, R Gribble, NT Fear, and D Murphy

Writing - Review and Editing: C Armour, E Spikol, E McGlinchey, R Gribble, NT Fear, and D Murphy

Visualization: C Armour, E Spikol, E McGlinchey, R Gribble, NT Fear, and D Murphy

Supervision: C Armour and NT Fear
Project Administration: C Armour, E Spikol, E

McGlinchey, and NT Fear

Funding Acquisition: C Armour, NT Fear, R Gribble, and D Murphy

\section{ETHICS APPROVAL}

$\mathrm{N} / \mathrm{A}$

\section{INFORMED CONSENT}

$\mathrm{N} / \mathrm{A}$

REGISTRY AND REGISTRATION NO. OF THE STUDY/TRIAL

$\mathrm{N} / \mathrm{A}$

ANIMAL STUDIES

$\mathrm{N} / \mathrm{A}$

\section{FUNDING}

This article received funding from Forces in Mind Trust (Project name: Understanding the psychosocial determinants of psychological health and well-being for Veteran families in the UK (FiMT / EO1901))

\section{PEER REVIEW}

This manuscript has been peer reviewed. 


\section{APPENDICES}

\section{Appendix 1}

\section{Search strings}

1. ti, ab (Veteran*) OR (Retired) OR (Ex-servi*) OR (Discharged) OR (Early service leaver) OR (Military) OR (Military Personnel) OR (Navy) OR (Army) OR (Air Force) OR (Military Family)) AND ((Military Family Member*) OR (Dependant*) OR (Spous*) OR (Wife) OR (Wives) OR (Husband*) OR (Partner*) OR (Parent*) OR (Mother*) OR (Father*) (Child*))

ti $=\left(\right.$ Veteran ${ }^{*}$ OR Retired OR Ex-servi ${ }^{*}$ OR Discharged OR Early service leaver OR Military OR Military Personnel OR Navy OR Army OR Air Force OR Military Family) AND ti $=$ (Military Family Member ${ }^{*}$ OR Dependant ${ }^{*}$ OR Spous* OR Wife OR Wives OR Husband* OR Partner* OR Parent* OR Mother* OR Father* OR

Child ${ }^{*}$ AND ab $=\left(\right.$ Veteran $^{*}$ OR Retired OR Ex-servi* OR Discharged OR Early service leaver OR Military OR Military Personnel OR Navy OR Army OR Air Force OR Military Family) AND ab $=$ (Military Family Member* OR Dependant* OR Spous* OR Wife OR Wives OR Husband* OR Partner* OR Parent* OR Mother* OR Father* OR Child*)

2. ti, ab (Veteran*) OR (Retired) OR (Ex-servi*) OR (Discharged) OR (Early service leaver) OR (Military) OR (Military Personnel) OR (Navy) OR (Army) OR (Air Force) OR (Military Family)) AND ((ti,ab. (Military Family Member*) OR (Dependant*) OR (Spous*) OR (Wife) OR (Wives) OR (Husband ${ }^{*}$ ) OR (Partner*) OR (Parent*) OR (Mother*) OR (Father $\left.{ }^{*}\right)\left(\right.$ Child $\left.\left.^{*}\right)\right)$ AND ((Depress* $\left.{ }^{*}\right)$ OR (Low mood) OR (Anxiet*) OR (Anxious) OR (Stress*) OR (Worry) OR (Post-traumatic stress disorder) OR (PTSD) OR (Trauma*) OR (Alcohol) OR (Alcohol abuse) OR (Alcohol misuse) OR (Alcohol dependence) OR (Problem drinking) OR (Substance*) OR (Substance abuse) OR (Substance misuse) OR (Substance dependence) OR (Drug*) OR (Drug* abuse) OR (Drug* misuse) OR (Drug* dependence))

ti $=($ Veteran* OR Retired OR Ex-servi* OR Discharged OR Early service leaver OR Military OR Military Personnel OR Navy OR Army OR Air Force OR Military Family) AND ti $=$ (Military Family Member $*$ OR Dependant ${ }^{*}$ OR Spous* OR Wife OR Wives OR Husband* OR Partner* OR Parent* OR Mother* OR Father* OR

Child $\left.{ }^{*}\right)$ AND ti $=($ Depress* OR Low mood OR Anxiet* OR Anxious OR Stress* OR Worry OR Post-traumatic stress disorder OR PTSD OR Trauma* OR Alcohol OR Alcohol abuse OR Alcohol misuse OR Alcohol dependence OR Problem drinking OR Substance* OR Substance abuse OR Substance misuse OR Substance dependence OR Drug* OR Drug* abuse OR Drug* misuse OR Drug* dependence) AND $\mathrm{ab}=\left(\right.$ Veteran $^{*}$ OR Retired OR Ex-servi* OR
Discharged OR Early service leaver OR Military OR Military Personnel OR Navy OR Army OR Air Force OR Military Family) AND ab $=$ (Military Family Member* OR Dependant* OR Spous* OR Wife OR Wives OR Husband* OR Partner* OR Parent* OR Mother* OR Father* OR Child $\left.{ }^{*}\right)$ AND ab $=$ (Depress* OR Low mood OR Anxiet ${ }^{*}$ OR Anxious OR Stress* OR Worry OR Post-traumatic stress disorder OR PTSD OR Trauma* OR Alcohol OR Alcohol abuse OR Alcohol misuse OR Alcohol dependence OR Problem drinking OR Substance* OR Substance abuse OR Substance misuse OR Substance dependence OR Drug* OR Drug* abuse OR Drug* misuse OR Drug* dependence)

3. ti, ab (Veteran*) OR (Retired) OR (Ex-servi*) OR (Discharged) OR (Early service leaver) OR (Military) OR (Military Personnel) OR (Navy) OR (Army) OR (Air Force) OR (Military Family)) AND ((Military Family Member*) OR (Dependant*) OR (Spous*) OR (Wife) OR (Wives) OR (Husband ${ }^{*}$ ) OR (Partner ${ }^{*}$ ) OR (Parent $\left.{ }^{*}\right)$ OR (Mother $\left.{ }^{*}\right)$ OR (Father*) (Child*)) AND ti, ab. (Psychosocial) OR (Psycholog*) OR (Psycholog* outcomes) OR (Mental health) OR (Mental illness) OR (Risk) OR (Resilience)) $\mathrm{ti}=($ Veteran* OR Retired OR Ex-servi* OR Discharged OR Early service leaver OR Military OR Military Personnel OR Navy OR Army OR Air Force OR Military Family) AND ti $=$ (Military Family Member* OR Dependant ${ }^{*}$ OR Spous* OR Wife OR Wives OR Husband* OR Partner* OR Parent* OR Mother* OR Father* OR Child ${ }^{*}$ AND ti $=$ (Psychosocial OR Psycholog* OR Psycholog* outcomes OR Mental health OR Mental illness OR Risk OR Resilience) OR $a b=($ Veteran* OR Retired OR Ex-servi* OR Discharged OR Early service leaver OR Military OR Military Personnel OR Navy OR Army OR Air Force OR Military Family) AND $a b=$ (Military Family Member ${ }^{*}$ OR Dependant ${ }^{*}$ OR Spous* OR Wife OR Wives OR Husband* OR Partner* OR Parent* OR Mother* OR Father* OR Child*) AND ab $=$ (Psychosocial OR Psycholog* OR Psycholog* outcomes OR Mental health OR Mental illness OR Risk OR Resilience)

4. ti, ab (Veteran*) OR (Retired) OR (Ex-servi*) OR (Discharged) OR (Early service leaver) OR (Military) OR (Military Personnel) OR (Navy) OR (Army) OR (Air Force) OR (Military Family)) AND ((ti,ab. (Military Family Member*) OR (Dependant*) OR (Spous*) OR (Wife) OR (Wives) OR (Husband*) OR (Partner*) OR (Parent*) OR (Mother $\left.{ }^{*}\right)$ OR (Father*) (Child*)) AND ((Depress*) OR (Low mood) OR (Anxiet*) OR (Anxious) OR (Stress*) OR (Worry) OR (Post-traumatic stress disorder) OR (PTSD) OR (Trauma*) OR (Alcohol) OR (Alcohol abuse) OR (Alcohol misuse) OR (Alcohol dependence) OR (Problem drinking) OR (Substance*) OR (Substance abuse) OR (Substance misuse) OR (Substance dependence) OR (Drug*) OR (Drug* abuse) OR (Drug* misuse) OR (Drug* dependence)) AND ((Psychosocial) OR (Psycholog*) OR (Psycholog* outcomes) OR (Mental health) OR (Mental illness) OR (Risk) OR (Resilience)) 


\section{Appendix 2}

\section{Quality assessment}

\begin{tabular}{|c|c|c|c|c|c|c|c|c|c|c|}
\hline Authors & Pub Year & Journal & Article Title & QA1 & QA2 & QA3 & QA4 & QA5 & QA6 & QA Total \\
\hline Alessi et al. & 2001 & $\begin{array}{l}\text { Journal } \\
\text { of Clinical } \\
\text { Psychology }\end{array}$ & $\begin{array}{l}\text { Personality and psychopathology } \\
\text { profiles of Veteran's wives: } \\
\text { Measuring distress using the } \\
\text { MMPI-2 }\end{array}$ & 1 & 1 & 1 & 1 & 0 & 1 & 5 \\
\hline T. Beks & 2016 & $\begin{array}{l}\text { The Qualitative } \\
\text { Report }\end{array}$ & $\begin{array}{l}\text { Walking on eggshells: The lived } \\
\text { experience of partners of Veterans } \\
\text { with PTSD }\end{array}$ & 1 & 1 & 1 & 1 & 0 & 1 & 5 \\
\hline $\begin{array}{l}\text { Campbell, } \\
\text { Renshaw, \& } \\
\text { Keith }\end{array}$ & 2012 & $\begin{array}{l}\text { Journal } \\
\text { of Family } \\
\text { Psychology }\end{array}$ & $\begin{array}{l}\text { Distress in spouses of Vietnam } \\
\text { Veterans: Associations with } \\
\text { communication about deployment } \\
\text { experiences }\end{array}$ & 1 & 1 & 1 & 1 & 1 & 1 & 6 \\
\hline $\begin{array}{l}\text { Calhoun, } \\
\text { Beckham, \& } \\
\text { Bosworth }\end{array}$ & 2002 & $\begin{array}{l}\text { Journal of } \\
\text { traumatic } \\
\text { stress }\end{array}$ & $\begin{array}{l}\text { Caregiver burden and psychological } \\
\text { distress in partners of Veterans } \\
\text { with chronic posttraumatic stress } \\
\text { disorder }\end{array}$ & 1 & 1 & 1 & 1 & 1 & 1 & 6 \\
\hline Cramm et al. & 2020 & $\begin{array}{l}\text { Military } \\
\text { Behavioral } \\
\text { Health }\end{array}$ & $\begin{array}{l}\text { Impact of Canadian Armed Forces } \\
\text { Veterans' mental health problems } \\
\text { on the family during the military to } \\
\text { civilian transition }\end{array}$ & 1 & 0 & 1 & 1 & 0 & 1 & 4 \\
\hline $\begin{array}{l}\text { Forrest, } \\
\text { Edwards, \& } \\
\text { Daraganova }\end{array}$ & 2018 & $\begin{array}{l}\text { International } \\
\text { Journal of } \\
\text { Epidemiology }\end{array}$ & $\begin{array}{l}\text { The intergenerational } \\
\text { consequences of war: Anxiety, } \\
\text { depression, suicidality, and mental } \\
\text { health among the children of war } \\
\text { Veterans }\end{array}$ & 1 & 1 & 1 & 1 & 1 & 1 & 6 \\
\hline $\begin{array}{l}\text { Gunter, } \\
\text { O'Toole, } \\
\text { Dadds, \& } \\
\text { Catts }\end{array}$ & 2020 & $\begin{array}{l}\text { Psychiatry } \\
\text { research }\end{array}$ & $\begin{array}{l}\text { Family emotional climate in } \\
\text { childhood and risk of PTSD in } \\
\text { adult children of Australian Vietnam } \\
\text { Veterans }\end{array}$ & 1 & 1 & 1 & 1 & 1 & 1 & 6 \\
\hline $\begin{array}{l}\text { Johnson, } \\
\text { Vidal, \& Lilly }\end{array}$ & 2018 & $\begin{array}{l}\text { Military } \\
\text { Medicine }\end{array}$ & $\begin{array}{l}\text { Absence of a link between } \\
\text { childhood parental military } \\
\text { service on depression and anxiety } \\
\text { disorders among college students }\end{array}$ & 1 & 1 & 1 & 1 & 1 & 1 & 6 \\
\hline Lee et al. & 2020 & $\begin{array}{l}\text { Military } \\
\text { Behavioral } \\
\text { Health }\end{array}$ & $\begin{array}{l}\text { A dyadic examination of drinking } \\
\text { behaviors within military-connected } \\
\text { couples }\end{array}$ & 1 & 1 & 1 & 1 & 1 & 1 & 6 \\
\hline $\begin{array}{l}\text { MacDonell, } \\
\text { Bhullar, \& } \\
\text { Thorsteinsson }\end{array}$ & 2016 & PeerJ & $\begin{array}{l}\text { Depression, anxiety, and stress } \\
\text { in partners of Australian combat } \\
\text { Veterans and military personnel: } \\
\text { A comparison with Australian } \\
\text { population norms }\end{array}$ & 1 & 1 & 1 & 1 & 1 & 1 & 6 \\
\hline $\begin{array}{l}\text { MacDonell, } \\
\text { Thorsteinsson, } \\
\text { Bhullar, \& Hine }\end{array}$ & 2014 & $\begin{array}{l}\text { Australian } \\
\text { Psychologist }\end{array}$ & $\begin{array}{l}\text { Psychological functioning of } \\
\text { partners of Australian combat } \\
\text { Veterans: Contribution of Veterans' } \\
\text { PTSD symptoms and partners' } \\
\text { caregiving distress }\end{array}$ & 1 & 1 & 1 & 1 & 1 & 1 & 6 \\
\hline $\begin{array}{l}\text { Manguno-Mire } \\
\text { et al. }\end{array}$ & 2007 & $\begin{array}{l}\text { Journal of } \\
\text { Nervous } \\
\text { and Mental } \\
\text { Disorders }\end{array}$ & $\begin{array}{l}\text { Psychological distress and burden } \\
\text { among female partners of combat } \\
\text { Veterans with PTSD }\end{array}$ & 1 & 1 & 1 & 1 & 1 & 1 & 6 \\
\hline
\end{tabular}

(Continued)

This advance access version may differ slightly from the final published version 
(Continued)

\begin{tabular}{|c|c|c|c|c|c|c|c|c|c|c|}
\hline Authors & Pub Year & Journal & Article Title & QA1 & QA2 & QA3 & QA4 & QA5 & QA6 & QA Total \\
\hline $\begin{array}{l}\text { McCormack, } \\
\text { Hagger, \& } \\
\text { Joseph }\end{array}$ & 2011 & $\begin{array}{l}\text { Journal of } \\
\text { Humanistic } \\
\text { Psychology }\end{array}$ & $\begin{array}{l}\text { Vicarious growth in wives } \\
\text { of Vietnam Veterans: A } \\
\text { phenomenological investigation Into } \\
\text { decades of "lived" experience }\end{array}$ & 1 & 1 & 1 & 1 & 0 & 1 & 5 \\
\hline $\begin{array}{l}\text { McCormack \& } \\
\text { Sly }\end{array}$ & 2013 & Traumatology & $\begin{array}{l}\text { Distress and growth: The subjective } \\
\text { "lived" experiences of being the } \\
\text { child of a Vietnam Veteran }\end{array}$ & 1 & 1 & 1 & 1 & 0 & 1 & 5 \\
\hline $\begin{array}{l}\text { Moriarty, } \\
\text { Winter, } \\
\text { Short, \& True }\end{array}$ & 2018 & $\begin{array}{l}\text { Journal of } \\
\text { Family Nursing }\end{array}$ & $\begin{array}{l}\text { Exploration of factors related to } \\
\text { depressive symptomatology in } \\
\text { family members of military Veterans } \\
\text { with traumatic brain injury }\end{array}$ & 1 & 1 & 1 & 0 & 1 & 1 & 5 \\
\hline $\begin{array}{l}\text { Murphy, } \\
\text { Palmer, \& } \\
\text { Busuttil }\end{array}$ & 2016 & $\begin{array}{l}\text { Journal } \\
\text { of Clinical } \\
\text { Medicine }\end{array}$ & $\begin{array}{l}\text { Mental health difficulties and help- } \\
\text { seeking beliefs within a sample of } \\
\text { female partners of UK Veterans } \\
\text { diagnosed with post-traumatic } \\
\text { stress disorder }\end{array}$ & 1 & 1 & 1 & 1 & 1 & 1 & 6 \\
\hline $\begin{array}{l}\text { Murphy, } \\
\text { Palmer, Hill, } \\
\text { Ashwick, \& } \\
\text { Walter }\end{array}$ & 2017 & $\begin{array}{l}\text { Journal of } \\
\text { Military, } \\
\text { Veteran and } \\
\text { Family Health }\end{array}$ & $\begin{array}{l}\text { Living alongside military PTSD: A } \\
\text { qualitative study of female partners' } \\
\text { experiences with UK Veterans }\end{array}$ & 1 & 1 & 1 & 1 & 1 & 1 & 6 \\
\hline O'Toole et al. & 2017 & $\begin{array}{l}\text { Acta } \\
\text { Psychiatrica } \\
\text { Scandinavica }\end{array}$ & $\begin{array}{l}\text { Intergenerational transmission of } \\
\text { post-traumatic stress disorder } \\
\text { in Australian Vietnam Veterans' } \\
\text { families }\end{array}$ & 1 & 1 & 1 & 1 & 1 & 1 & 6 \\
\hline $\begin{array}{l}\text { O'Toole, } \\
\text { Outram, Catts, } \\
\text { \& Pierse }\end{array}$ & 2010 & $\begin{array}{l}\text { Journal of } \\
\text { Nervous \& } \\
\text { Mental Disease }\end{array}$ & $\begin{array}{l}\text { The mental health of partners of } \\
\text { Australian Vietnam Veterans three } \\
\text { decades after the war and its } \\
\text { relation to Veteran military service, } \\
\text { combat, and PTSD }\end{array}$ & 1 & 1 & 1 & 1 & 1 & 1 & 6 \\
\hline O'Toole et al. & 2018 & $\begin{array}{l}\text { Psychiatry } \\
\text { Research }\end{array}$ & $\begin{array}{l}\text { Growing up with a father with } \\
\text { PTSD: The family emotional climate } \\
\text { of the children of Australian Vietnam } \\
\text { Veterans }\end{array}$ & 1 & 1 & 1 & 1 & 1 & 1 & 6 \\
\hline O'Toole et al. & 2018 & $\begin{array}{l}\text { International } \\
\text { Journal of } \\
\text { Epidemiology }\end{array}$ & $\begin{array}{l}\text { The mental health of sons and } \\
\text { daughters of Australian Vietnam } \\
\text { Veterans }\end{array}$ & 1 & 1 & 1 & 1 & 1 & 1 & 6 \\
\hline O'Toole et al. & 2015 & $\begin{array}{l}\text { Journal of } \\
\text { Psychiatric } \\
\text { Research }\end{array}$ & $\begin{array}{l}\text { Suicidality in Australian Vietnam } \\
\text { Veterans and their partners }\end{array}$ & 1 & 1 & 1 & 1 & 1 & 1 & 6 \\
\hline Outram et al. & 2009 & $\begin{array}{l}\text { Australian } \\
\text { Psychologist }\end{array}$ & $\begin{array}{l}\text { Still living in a war zone: Perceived } \\
\text { health and wellbeing of partners } \\
\text { of Vietnam Veterans attending } \\
\text { partners' support groups in New } \\
\text { South Wales, Australia }\end{array}$ & 1 & 1 & 1 & 1 & 0 & 1 & 6 \\
\hline Saban et al. & 2016 & $\begin{array}{l}\text { Biological } \\
\text { Research for } \\
\text { Nursing }\end{array}$ & $\begin{array}{l}\text { The man I once knew: Grief and } \\
\text { inflammation in female partners of } \\
\text { Veterans with traumatic brain injury }\end{array}$ & 1 & 1 & 1 & 1 & 1 & 1 & 6 \\
\hline
\end{tabular}

